\title{
21-Hydroxylase deficiency in Brazil
}

T.A.S.S. Bachega ${ }^{1}$,

A.E.C. Billerbeck ${ }^{1}$,

G. Madureira ${ }^{1}$,

J.A.M. Marcondes ${ }^{1}$,

C.A. Longui ${ }^{2}$, M.V. Leite ${ }^{3}$,

I.J.P. Arnhold ${ }^{1}$ and

B.B. Mendonça ${ }^{1}$

\author{
${ }^{1}$ Unidade de Endocrinologia do Desenvolvimento e Laboratório de Hormônios e \\ Genética Molecular, Disciplina de Endocrinologia, Hospital das Clínicas, \\ Faculdade de Medicina, U niversidade de São Paulo, São Paulo, SP, Brasil \\ ${ }^{2}$ Serviço de Endocrinologia Pediátrica, Departamento de Pediatria, Santa Casa, \\ São Paulo, SP, Brasil \\ ${ }^{3}$ Departamento de Clínica Médica I, U niversidade Federal do Rio Grande do Norte, \\ Natal, RN, Brasil
}

\section{Correspondence \\ B.B. Mendonça \\ Divisão de Endocrinologia \\ Hospital das Clínicas, FM , USP \\ Caixa Postal 3671 \\ 01060-970 São Paulo, SP \\ Brasil \\ Fax: + 55-11-883-0626 \\ E-mail: beremen@usp.br \\ Presented at the First \\ International Meeting on Adrenal \\ Disease: Basic and Clinical \\ Aspects, Ribeirão Preto, SP, Brazil, \\ August 31-September 2, 1999. \\ Research partially supported by FAPESP (No. 95/8325-6) and CNPq (No. 140.745/93-9). T.A.S.S. Bachega was supported by a grant from FAPESP (No. 98/00243-9).}

Received December 20, 1999 Accepted March 29, 2000

\section{Abstract}

We determined the frequency of large rearrangements and point mutations in 130 Brazilian patients with 21-hydroxylase deficiency and correlated genotype with phenotype. The frequency of CYP21 deletions was lower (4.4\%) than in most of the previous series described, whereas the frequency of large gene conversions was similar to the frequency reported in the literature (6.6\%). The most frequent point mutations were I2 splice ( $41.8 \%$ in salt wasting - SW), I172N (32.6\% in simple virilizing - SV) and V281L ( $40.2 \%$ in the late onset form - LO). The frequency of the nine most common point mutations was similar to that reported for other countries. The 93 fully genotyped patients were classified into 3 mutation groups based on the degree of enzymatic activity ( $\mathrm{A}<2 \%, \mathrm{~B} \cong 2 \%, \mathrm{C}>20 \%)$. In group $\mathrm{A}$, $62 \%$ of cases presented the SW form; in group B, $96 \%$ the SV form, and in group C, $88 \%$ the $\mathrm{LO}$ form. We diagnosed $80 \%$ of the affected alleles after screening for large rearrangements and 15 point mutations. To diagnose these remaining alleles we sequenced the CYP21 gene of one patient with the SV form and identified a heterozygous $\mathrm{G} \rightarrow \mathrm{A}$ transition in codon 424 . This mutation leads to a substitution of glycine by serine in a conserved region and was also found in a compound heterozygous state in 4 other patients. The mutation G424S presented a linkage disequilibrium with $\mathrm{CYP} 21 \mathrm{P}$ and $\mathrm{C} 4 \mathrm{~A}$ gene deletions and HLA DR17, suggesting a probable founder effect. Search for the G424S mutation in other populations will reveal if it is restricted to the Brazilian patients or if it has a wider ethnic distribution.

\section{Introduction}

Congenital adrenal hyperplasia $(\mathrm{CAH})$ due to 21 -hydroxylase $(21 \mathrm{OH})$ deficiency is the most frequent inborn error of metabolism and accounts for $90-95 \%$ of CAH cases $(1,2)$. The spectrum of clinical manifestations includes a severe form (classical) with prenatal virilization of external genitalia in the female

\section{Key words}

- 21-Hydroxylase deficiency

- Congenital adrenal

hyperplasia

- Brazilian patients

- CYP21 mutations

- Genotype

- Phenotype fetus and post-natal virilization in both sexes, with or without salt wasting, and a milder form (non-classical) whose carriers remain asymptomatic or develop symptoms during childhood or at puberty (1).

The structural gene (CYP21) for the $21 \mathrm{OH}$ enzyme is located in the HLA class III region on the short arm of chromosome 6 (6p21.3) together with the pseudogene which is $98 \%$ 
identical. Both genes alternate in tandem with the C4B and C4A genes (3-5). Because of the high homology and tandem-repeat organization of the CYP2 1 and $\mathrm{C} 4$ genes this region of the genome is subject to unequal crossover events and gene conversions $(6,7)$. The mutations that account for $21 \mathrm{OH}$ deficiency can be CYP21 deletions, large gene conversions or point mutations. The aim of our study was to determine the frequency of large mutations by Southern blotting analysis and the frequency of point mutations by allele-specific polymerase chain reaction (PCR) in 130 Brazilian patients with the classical and non-classical forms of $21 \mathrm{OH}$ deficiency and correlate genotype with phenotype.

\section{Patients and Methods}

\section{Patients}

All families gave informed consent to participate in the genetic study. We studied $130 \mathrm{CAH}-21 \mathrm{OH}$ patients (97 Caucasians, 24 Brazilian Mulattoes, 7 Blacks, and 2 Asians) (110 genetic females) from 116 families, four of them related. One subject was affected in 106 families, 2 were affected in 8 families ( 2 of these families included one affected parent) and 4 were affected in 2 families ( 1 of these families with one affected parent). Five families were consanguineous. We also studied 132 parents and 22 normal siblings. The patients were classified into one of the 3 clinical forms of $\mathrm{CAH}-$ $21 \mathrm{OH}$ defined according to standard criteria (7). Among the 130 patients, 29 presented the salt-wasting (SW) form, 51 the simple virilizing (SV) form and 50 the late onset (LO) form. The SW form was characterized by extremely elevated concentrations of 17 hydroxyprogesterone (17OHP) and plasma renin activity (PRA), hyperkalemia, hyponatremia, and dehydration in the first months of life. All females had ambiguous genitalia graded according to Prader staging.
The SV form was characterized by ambiguous genitalia in females, sexual precocity in males without salt wasting and elevated 17OHP and PRA levels. Height and bone age were advanced. The $L O$ form was characterized in girls by normal external genitalia, or mild clitoral enlargement and in both sexes by precocious pubarche and stimulated $17 \mathrm{OHP}>10 \mathrm{ng} / \mathrm{ml}$ (mean +2 SD of ACTH-stimulated 17OHP levels in obligate heterozygotes studied in our laboratory).

\section{Hormone assays}

Serum hormones were measured by radioimmunoassay (8). PRA was measured with commercial kits from CIS Bio International (Gif-Sur-Yvette, France).

\section{Molecular studies}

DNA samples were obtained from peripheral blood leukocytes by standard procedures.

\section{Southern blotting studies}

Ten $\mu \mathrm{g}$ of DNA was digested separately with the restriction enzymes TaqI and BglII (Gibco BRL, Gaithersburg, MD, USA) according to manufacturer instructions, submitted to electrophoresis on $1 \%$ agarose gels and transferred to nylon membranes (9). The membrane was prehybridized at $42^{\circ} \mathrm{C}$ for $4 \mathrm{~h}$ in 5X SSPE, 0.1\% Denhardt's solution, 5\% dextran sulfate, $1 \%$ sodium dodecyl sulfate (SDS), $0.2 \mathrm{mg} / \mathrm{ml}$ denatured salmon sperm DNA, and $50 \%$ formamide. Hybridization with a radioactive probe was performed after prehybridization at $42^{\circ} \mathrm{C}$ for $24 \mathrm{~h}$. The blots were then washed in $0.1 \mathrm{X} \mathrm{SSC}$ and $0.1 \%$ SDS for $30 \mathrm{~min}$ at $65^{\circ} \mathrm{C}$ and exposed to Kodak XAR-5 films for $5-15$ days at $-80^{\circ} \mathrm{C}$ with intensifying screens. This procedure was performed to determine the CYP2 1 and $\mathrm{C} 4$ gene copy number. The number of copies 
of a fragment was determined by comparing its signal intensity with those from other fragments in the same electrophoretic lane and also determined by densitometry using a Personal Densitometer from Molecular Dynamics (Sunnyvale, CA, USA).

Allele-specific PCR as described by Wilson et al. (10) was used for the determination of 8 point mutations (P30L, I2 splice, Del 8nt, I172N, Cluster, V281L, Q318X, R356W). Positive and negative control DNA was used in all reactions. Allele-specificPCR methodology described by Wedell and Luthman (11) was used for identification of the $\mathrm{T}$ insertion (Ins T) on exon 7, P453S, G291S, I7 splice, W405X, R483P, R483 $\rightarrow$ frameshift.

\section{Genotype categories}

The patients were divided into 3 different genotype groups according to the impairment of enzymatic activity as described by Speiser et al. (12). Group A included patients who were homozygous for mutations that predict $0 \%$ overall activity (subgroup A1) and patients who were homozygous for I2 splice or compound heterozygous with mutations from group A1 (low, but measurable enzymatic activity - subgroup A2). Group B included patients who were homozygous for I172N ( $2 \%$ of the enzymatic activity) or compound heterozygous with mutations from group A. Group C included patients who were homozygous for P30L, V281L and P453S (20 to 50\% of enzymatic activity) or compound heterozygous with mutations from groups A or B.

\section{Statistical analysis}

The chi-square test was used to analyze the association of each mutation with each clinical form. Differences in basal levels of 17OHP, testosterone and androstenedione among the three genotype groups were evaluated using the Kruskal-Wallis test.

\section{Results and Discussion}

This paper describes the largest study conducted on a Latin-American population and includes the three forms of congenital adrenal hyperplasia due to $21 \mathrm{OH}$ deficiency.

In our series, the frequency of CYP21P deletions and duplications found in patients and in the normal alleles of their parents was similar to those reported in the literature (13). We found $0.9 \%$ of CYP2 1 duplications which is a rare rearrangement in $\mathrm{CAH}$ alleles. These duplications per se are not responsible for $\mathrm{CAH}$, except when both genes carry a point mutation.

The frequency of large gene conversions in our study was $6.6 \%$, similar to the frequency reported in the literature (12-15). The frequency of CYP2 1 deletions in classical and non-classical $21 \mathrm{OH}$ deficiency was lower (4.4\%) than in most of the previous series described, even if we consider only the classical form $(6.3 \%)(12,14)$. However, our data are similar to those obtained by Araujo et al. (16), who found 7.3\% of CYP21 deletions in 41 unrelated chromosomes from Brazilian patients with the classical form of $21 \mathrm{OH}$ deficiency, and by Dardis et al. (17), who found $6.9 \%$ of CYP2 1 deletions in 72 alleles in an Argentinean population with the classical form. Similarly, a lower frequency of CYP21 deletions (less than 1\%) was also found in a Mexican population (18). In the present Brazilian cohort Southern blotting studies detected CYP21 deletions and large gene conversion in only $11 \%$ of alleles, suggesting a higher incidence of point mutations in our series (19).

About 40 point mutations have been described for the $21 \mathrm{OH}$ gene. Most of the patients are compound heterozygotes, and the clinical form correlates to the mutated allele with higher enzymatic activity $(12,20-$ 22). In the 228 unrelated alleles of our series, the most frequent point mutations were I2 splice (20.6\%), I172N (14\%) and V281L (18\%). In the SW form the most frequent 
mutation was I2 splice (41.8\%), in the SV form the most frequent one was $I 172 \mathrm{~N}$ (32.6\%), followed by I2 splice (16.3\%). In the $\mathrm{LO}$ form the most frequent mutation was V281L (40.2\%), followed by I2 splice (5.7\%) and P30L (4.6\%). There was a significant association of I2 splice, I172N and V281L with the SW, SV and LO forms, respectively $(\mathrm{P}<0.0001)$. Point mutations were present in 158 alleles. Ten $(6.3 \%)$ of these alleles presented two or three point mutations: I2 splice + V281L (2 alleles), I2 splice + Ins T, P30L + R356W, Ins T + Q318X + R356W, Q318X + R356W, I172N + Cluster, I2 splice + R356W, I172N + V281L, I2 splice + Del 8 nt. There were two de novo mutations $(0.9 \%)$, both of them $I 172 \mathrm{~N}$, one of maternal origin and the other of paternal origin. Maternity and paternity were confirmed with multiple polymorphic markers (23).

When searching for the mutations of index cases in their parents, we diagnosed three asymptomatic affected mothers, two of them homozygous for V281L and the other with the V281L/R356W genotype. The latter mother had three affected children, one with the SV form and two with the LO form.

Ninety-three patients had mutations identified in both alleles. Of these patients, 34 presented the group A genotype (21 with the SW form and 13 with the SV form), 26 presented the group B genotype (25 with SV and one with the LO form), and 33 presented the group C genotype (29 with the LO form and 4 with the SW form). Virilization of the external genitalia ranged from Prader II to V in group A and from Prader II to IV in group B.

Basal 17OHP levels in groups A, B and C ranged from 38 to $500(228 \pm 160), 8.7$ to $385(152 \pm 114)$ and 0.3 to $227(27.8 \pm 45)$ $\mathrm{ng} / \mathrm{ml}$, respectively $(\mathrm{P}<0.0001)$. In group $\mathrm{C}$, ACTH-stimulated 17OHP levels ranged from 17 to $121(58 \pm 30) \mathrm{ng} / \mathrm{ml}$. Basal testosterone levels ranged from 75 to 408 (208 \pm 117$), 53$ to $282(112 \pm 72)$ and 10 to $450(68 \pm 54) \mathrm{ng} /$ $\mathrm{dl}$ in groups $\mathrm{A}, \mathrm{B}$ and $\mathrm{C}$, respectively
$(\mathrm{P}<0.0001)$. Basal androstenedione levels ranged from 3.5 to $19(8.5 \pm 5), 3.1$ to $21(8.0$ $\pm 5.4)$ and 0.2 to $10(2.1 \pm 2.0) \mathrm{ng} / \mathrm{ml}$ in groups $\mathrm{A}, \mathrm{B}$ and $\mathrm{C}$, respectively $(\mathrm{P}<0.0001)$. PRA levels ranged from 2.8 to $22(12.8 \pm$ 5.8) and 3 to $21(8.8 \pm 5.4) \mathrm{ng} \mathrm{ml}^{-1} \mathrm{~h}^{-1}$ in groups $\mathrm{A}$ and $\mathrm{B}$, respectively.

We observed a good correlation of genotype with 17OHP, testosterone and androstenedione levels, which reflects the degree of enzymatic activity impairment. The intensity of hyperandrogenism was correlated with the severity of neonatal external genitalia virilization found in group $\mathrm{A}$.

The Brazilian population is ethnically heterogenous, consisting mainly of Portuguese ancestry and interracial marriages with Blacks and Native Indians. The most frequent mutations in our series were those also present in the pseudogene, similarly to previous reports $(12,14,20,24,25)$, except for the Del $8 \mathrm{nt}$ mutation, which is normally associated with the classical form and was detected only in heterozygosis in the LO form. Studies involving approximately 10 mutations, comprising large and point mutations, diagnosed 77.6 to $95 \%$ of the alleles $(12,14,17,25)$. Even though we screened for 17 mutations, we had a significant number of unidentified alleles (20\%). Higher numbers of undiagnosed alleles were also observed in other Latin-American studies $(17,21)$. Since rare mutations were also scarcely found or even absent in our alleles, we suppose that new mutations might be present in our population, as observed in a Mexican study (21). The highest frequency of undiagnosed alleles in our series was found in the LO form, as well as in other large series $(14,25)$. However, we did not rule out the presence of other rare mutations such as P105L, R339H or promoter mutations that have been found in the LO form (26). On the other hand, the lowest value of ACTH-stimulated 17OHP levels in LO patients, in whom mutations in both alleles were determined, was $17 \mathrm{ng} / \mathrm{ml}$. These data 
suggest that the cutoff value of $10 \mathrm{ng} / \mathrm{ml}$ for stimulated 17OHP levels might have overestimated the diagnosis of the non-classical form of CAH-21OH (27). Genotyping patients with the LO form will support the definition of a new cutoff value for ACTHstimulated 17OHP levels.

We observed a good correlation between genotype and phenotype, also found in other populations (12,20-23). The worst correlation occurred in group A, where the mutations $\mathrm{I} 2$ splice and R356W, that are generally associated with the SW form, were also present in 10 patients with the SV form. The association between $\mathrm{I} 2$ splice and $\mathrm{SV}$ form has been previously described (24), and can be explained by different degrees of normally spliced mRNA. Discordance between genotype and phenotype was found in four patients with the SW form and with a mild mutation in one of the alleles. We cannot rule out the presence of an additional new mutation in these alleles or of regulatory abnormalities. Because of some discordance between phenotype and genotype, phenotype prediction must be made with caution in prenatal diagnosis based on molecular genetic analysis of fetal DNA. Parents that are compound heterozygotes for mutations with different enzymatic activities can generate offspring with different genotypes, a fact explaining the different phenotypes observed among siblings.

Considering our previous screening for large mutations (19) and for point mutations
(23), we diagnosed $80 \%$ of all alleles, $93 \%$ of them in SW, 83\% in SV and 69\% in LO. This result suggests the presence of new mutations in Brazilian patients with different clinical forms of CAH-21OH. In order to diagnose these alleles we sequenced the entire CYP2 1 gene of one Mulatto patient with the simple virilizing form, who had only the R356W mutation in a heterozygous state. We identified a heterozygous $\mathrm{G} \rightarrow \mathrm{A}$ transition in codon 424 (28). This mutation leads to a substitution of glycine by serine in a conserved region where glycine is conserved in at least 4 species. This novel mutation eliminates one of the restriction sites of the BanI enzyme, which made its screening possible for the whole series. The G424S mutation was found in a compound heterozygous state in 5 families: 4 presented the simple virilizing form and one, the non-classical form. Interestingly, 3 out of 5 families are of Mulatto origin. This mutation was not identified in the $118 \mathrm{CYP} 21$ alleles of normal individuals, ruling out the possibility of polymorphism, or in 80 pseudogenes, indicating a random mutagenic event and not a microconversion event. All patients with the G424S mutation presented CYP21P and C4A gene deletions and HLA DR17 in the same haplotype, suggesting a linkage disequilibrium and a probable founder effect. A search for the G424S mutation in other populations will reveal if it is restricted to Brazilian patients or if it has a wider ethnic distribution.

\section{References}

1. New MI, White PC, Pang S, Dupont B \& Speiser PW (1989). The adrenal hyperplasias. In: Scriver CR, Beaudet AL, Sly S \& Valle $D$ (Editors), The Metabolic Basis of Inherited Disease. McGraw-Hill Inc., New York, 1881-1918.

2. Morel Y \& Miller WL (1991). Clinical and molecular genetics of congenital adrenal hyperplasia due to 21-hydroxylase deficiency. In: Harris H \& Hirschhorn K (Edi- tors), Advance of Human Genetics. Vol. 20. Plenum Press, New York, 1-68.

3. Carroll MC, Campbell RD \& Porter RR (1985). Mapping of steroid 21-hydroxylase genes adjacent to complement component $\mathrm{C} 4$ genes in HLA, the major histocompatibility complex in man. Proceedings of the National Academy of Sciences, USA, 82: 521-525.

4. White PC, New MI \& Dupont B (1986).
Structure of human steroid 21-hydroxylase genes. Proceedings of the National Academy of Sciences, USA, 83: 51115115.

5. Higashi Y, Yoshioka H, Yamane M, Gotoh O \& Fujii-Kuriyama $Y$ (1986). Complete nucleotide sequence of two steroid 21hydroxylase genes tandemly arranged in human chromosome: a pseudogene and a genuine gene. Proceedings of the $\mathrm{Na}$ - 
tional Academy of Sciences, USA, 83: 2841-2845.

6. Higashi $\mathrm{Y}$, Tanae $\mathrm{A}$, Inoue $\mathrm{H} \&$ FujiiKuriyama $Y$ (1988). Evidence for frequent gene conversions in the steroid 21-hydroxylase (P-450c21) gene: implications for steroid 21-hydroxylase deficiency. American J ournal of Human Genetics, 42: 17-25.

7. New MI, Lorenzen F, Lerner AJ , Kohn B, Oberfield SE, Pollack MS, Dupont B, Stoner E, Levy DJ , Pang S \& Levine LS (1983). Genotyping steroid 21-hydroxylase deficiency: hormonal reference data. J ournal of Clinical Endocrinology and Metabolism, 57: 320-326.

8. Abraham G (1974). Radioimmunoassay of steroids in biological materials. Acta Endocrinologica, 75: 1-42.

9. Southern EM (1975). Detection of specific sequences among DNA fragments separated by gel electrophoresis. J ournal of Molecular Biology, 98: 503-517.

10. Wilson RC, Wei J Q, Cheng KC, Mercado AB \& New MI (1995). Rapid deoxyribonucleic acid analysis by allele-specific polymerase chain reaction for detection of mutations in the steroid 21-hydroxylase gene. J ournal of Clinical Endocrinology and Metabolism, 80: 1635-1640.

11. Wedell A \& Luthman H (1993). Steroid 21-hydroxylase deficiency: two additional mutations in salt wasting disease and rapid screening of disease-causing mutations. Human Molecular Genetics, 2: 499504.

12. Speiser PW, Dupont J, Zhu D, Serrat J, Buegeleisen $M$, Tusié-Luna MT, Lesser M, New MI \& White PC (1992). Disease expression and molecular genotype in congenital adrenal hyperplasia due to 21hydroxylase deficiency. J ournal of Clinical Investigation, 90: 584-595.

13. Rumsby G, Carroll MC, Porter RR, Grant DB \& Hjelm M (1986). Deletion of the steroid 21-hydroxylase and complement C4 genes in congenital adrenal hyperplasia. J ournal of Medical Genetics, 23: 204209.

14. Mornet $E$, Crété $P$, Kuttenn $F$, RauxDemay M-C, Boué J , White PC \& Boué A (1991). Distribution of deletions and seven point mutations on CYP21 genes in three clinical forms of steroid 21-hydroxylase deficiency. American J ournal of Human
Genetics, 48: 79-88.

15. Morel $Y$, Murena $M$, Nicolino $M \&$ Forest MG (1992). Molecular genetics of the congenital adrenal hyperplasia due to 21-hydroxylase deficiency. In: Saez JM, Brownie AC, Capponi A, Chambaz EM \& Mantero $\mathrm{F}$ (Editors), Cellular and Molecular Biology of the Adrenal Cortex. Vol. 222. Colloque INSERM/J ohn Libbey Eurotext Ltd., France, 123-136.

16. Araujo M, Sanches MR, Suzuki LA, Guerra J r G, Farah SB \& Mello MP (1996). M olecular analysis of CYP21 and C4 genes in Brazilian families with the classical form of steroid 21-hydroxylase deficiency. Brazilian J ournal of Medical and Biological Research, 29: 1-13.

17. Dardis A, Bergada I, Bergada C, Rivarola M \& Belgorosky A (1997). Mutations of the steroid 21-hydroxylase gene in an Argentinean population of 36 patients with classical congenital adrenal hyperplasia. J ournal of Pediatric Endocrinology and Metabolism, 10: 55-61.

18. Tusié-Luna $M T$, Ramírez-J iménez $S$, Ordóñez-Sanchez ML, Cabello-Villegas J , Altamirano-Bustamante $\mathrm{N}$, Calzada-León $\mathrm{R}$, Robles-Valdés C, Mendoza-Morfín F, Méndez J P \& Terán-García M (1996). Low frequency of deletion alleles in patients with steroid 21-hydroxylase deficiency in a Mexican population. Human Genetics, 98: 376-379.

19. BachegaTASS, Billerbeck AEC, Madureira G, Arnhold IJ P, Medeiros MA, Marcondes J AM, Longui CA, Nicolau W, Bloise W \& Mendonça BB (1999). Low frequency of CYP21 deletions in Brazilian patients with congenital adrenal hyperplasia due to 21hydroxylase deficiency. Human Heredity, 49: 9-14.

20. Wedell A, Thilén A, Ritzén EM \& Stengler B (1994). Mutational spectrum of the steroid 21-hydroxylase gene in Sweden: implications for genetic diagnosis and association with disease manifestation. J ournal of Clinical Endocrinology and Metabolism, 78: 1145-1152.

21. Ordoñez-Sánchez $M L$, Ramírez-J iménez S, López-Gutierrez AU, Riba L, GamboaCardiel S, Cerrillo-Hinojosa M, AltamiranoBustamante N, Calzada-Léon R, RoblesValdés C, Mendonza-Morfín $\mathrm{F} \&$ TusiéLuna MT (1998). Molecular genetic analysis of patients carrying steroid 21-hydroxy- lase deficiency in the Mexican population: identification of possible new mutations and high prevalence of apparent germline mutations. Human Genetics, 102: 170-177.

22. J ääskeläinen J, Levo $A$, Voutilainen $R \&$ Partanen J (1997). Population-wide evaluation of disease manifestation in relation to molecular genotype in steroid 21-hydroxylase (CYP21) deficiency: good correlation in a well defined population. J ournal of Clinical Endocrinology and Metabolism, 82: 3293-3297.

23. Bachega TASS, BillerbeckAEC, Madureira G, Marcondes J AM, Longui CA, Leite MV, Arnhold IJ P \& Mendonça BB (1998). Molecular genotype in Brazilian patients with classical and nonclassical forms of 21-hydroxylase deficiency. J oumal of Clinical Endocrinology and Metabolism, 83: 44164419.

24. Carrera P, Bordone L, Azzani T, Brunelli V Garancini MP, Chiumello G \& Ferrari M (1996). Point mutations in Italian patients with classic, non-classic, and cryptic forms of steroid 21-hydroxylase deficiency. Human Genetics, 98: 662-665.

25. Ezquieta B, Oliver A, Gracia R \& Gancedo PG (1995). Analysis of steroid 21-hydroxylase gene mutations in the Spanish population. Human Genetics, 96: 198-204.

26. Helmberg A, Tusié-Luna MT, Tabarelli M, Kofler R \& White PC (1992). R339H and P453S: CYP21 mutations associated with nonclassic steroid 21-hydroxylase deficiency that are not apparent gene conversions. Molecular Endocrinology, 6: 13181322.

27. Bachega TASS, Billerbeck AEC, Marcondes J AM, Madureira G, Arnhold IJ P \& Mendonça BB (2000). Influence of different genotypes on 17-hydroxyprogesterone levels in patients with nonclassical congenital adrenal hyperplasia due to 21hydroxylase deficiency. Clinical Endocrinology (in press).

28. Billerbeck AEC, Bachega TASS, Frazzatto ET, Nishi MY, Goldberg AC, Marin MLC, Madureira G, Monte O, Arnhold IJP \& Mendonça BB (1999). A novel missense mutation Gly424Ser in Brazilian patients with 21-hydroxylase deficiency. J ournal of Clinical Endocrinology and Metabolism, 84: 2870-2872. 